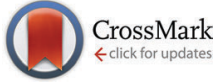

Cite this: Phys. Chem. Chem. Phys., $2015,17,8000$

Received 11th December 2014, Accepted 20th February 2015

DOI: $10.1039 / c 4 c p 05786 d$

www.rsc.org/pccp

\section{Thermal relaxation of lithium dendrites $\uparrow$}

\author{
Asghar Aryanfar, ${ }^{\star a}$ Daniel J. Brooks, ${ }^{b}$ Agustín J. Colussi, ${ }^{\star a}{ }^{\text {B Boris V. Merinov, }}{ }^{b}$ \\ William A. Goddard III ${ }^{\mathrm{b}}$ and Michael R. Hoffmann ${ }^{\mathrm{a}}$
}

\begin{abstract}
The average lengths $\bar{\lambda}$ of lithium dendrites produced by charging symmetric $\mathrm{Li}^{\mathrm{O}}$ batteries at various temperatures are matched by Monte Carlo computations dealing both with $\mathrm{Li}^{+}$transport in the electrolyte and thermal relaxation of $\mathrm{Li}^{0}$ electrodeposits. We found that experimental $\bar{\lambda}(T)$ variations cannot be solely accounted by the temperature dependence of $\mathrm{Li}^{+}$mobility in the solvent but require the involvement of competitive $\mathrm{Li}$-atom transport from metastable dendrite tips to smoother domains over $\Delta E_{\mathrm{R}}^{*} \sim 20 \mathrm{~kJ} \mathrm{~mol}^{-1}$ barriers. A transition state theory analysis of $\mathrm{Li}$-atom diffusion in solids yields a negative entropy of activation for the relaxation process: $\Delta S_{\mathrm{R}}^{+} \approx-46 \mathrm{~J} \mathrm{~mol}^{-1} \mathrm{~K}^{-1}$ that is consistent with the transformation of amorphous into crystalline $\mathrm{Li}^{\mathrm{O}}$ electrodeposits. Significantly, our $\Delta E_{\mathrm{R}}^{\mathrm{*}} \sim 20 \mathrm{~kJ} \mathrm{~mol}^{-1}$ value compares favorably with the activation barriers recently derived from DFT calculations for self-diffusion on $\mathrm{Li}^{\circ}(001)$ and (111) crystal surfaces. Our findings suggest a key role for the mobility of interfacial Li-atoms in determining the morphology of dendrites at temperatures above the onset of surface reconstruction: $T_{\mathrm{SR}} \approx 0.65$ $T_{\mathrm{MB}}\left(T_{\mathrm{MB}}=453 \mathrm{~K}\right.$ : the melting point of bulk $\left.\mathrm{Li}^{\mathrm{O}}\right)$.
\end{abstract}

\section{Introduction}

Portable electronic devices and intermittent renewable energy sources demand high-capacity, reliable, long-lasting electric energy storage units. ${ }^{1-3}$ The low mass density $\left(0.564 \mathrm{~g} \mathrm{~cm}^{-3}\right)$ and high reduction potential $\left(E^{0}=-3.04 \mathrm{~V} v s\right.$. SHE) of lithium metal $\left(\mathrm{Li}^{0}\right)$ should make it the ideal electrode material. ${ }^{4-8} \mathrm{Li}^{0}$, however, is exceptionally prone to grow dendrites under the far from equilibrium conditions prevalent during electrodeposition. ${ }^{4,9-15}$ The runaway growth of metallic dendrites is the harbinger of short-circuiting, overheating, and ultimately the ignition of the organic solvents used in $\mathrm{Li}^{0}$ batteries. ${ }^{16}$ Intense efforts are therefore underway to prevent such hazards by limiting dendrite growth during battery charging. ${ }^{16-19}$

At present, efforts aimed at controlling $\mathrm{Li}^{0}$ dendrite growth remain semi-empirical because its mechanism is not fully understood. ${ }^{19-33}$ Models fall short of capturing the complex dynamics of dendrite inception and growth, ${ }^{21,34,35}$ or accounting for the peculiar facility of $\mathrm{Li}^{0}$ to grow dendrites relative to other potentially useful 1st- and 2nd-period metals. ${ }^{36-45}$ In our view control strategies should consider that dendrite growth is a nondeterministic stochastic process, ${ }^{46-51}$ and the propensity of $\mathrm{Li}^{0}$

\footnotetext{
${ }^{a}$ Linde Center for Global Environmental Science, California Institute of Technology, Pasadena, CA 91125, USA.E-mail: aryanfar@caltech.edu,ajcoluss@caltech.edu

${ }^{b}$ Materials \& Process Simulation Center, California Institute of Technology, Pasadena, CA 91125, USA

$\dagger$ Electronic supplementary information (ESI) available. See DOI: 10.1039/ c4cp05786d
}

for growing dendrites a direct consequence of the inherent $\mathrm{Li}-\mathrm{Li}$ binding energy and energy barrier values for Li-atom transport on the metal surface. ${ }^{52-54}$ We have previously addressed the former issue via pulsed charging experiments and Monte Carlo computations. ${ }^{46}$ Here we report experiments and computations aimed at quantifying the thermal behavior of electrolytic $\mathrm{Li}^{0}$ dendrites as a first step toward linking $\mathrm{Li}^{0}$ properties with dendrites growth control. ${ }^{55-57}$

Our experiments consist of charging symmetric coin $\mathrm{Li}^{0}$ batteries that allow for in situ visualization of dendrites. ${ }^{58-60}$ Disk electrodes $\left(\right.$ area $=1.6 \mathrm{~cm}^{2}$ ) punched from cleaned $\mathrm{Li}^{0}$ foil (Aldrich, 99.9\%) $0.38 \mathrm{~mm}$ thick were mounted $L=3.175 \mathrm{~mm}$ apart on an open-ended transparent polymethyl-methacrylate (PMMA) cylindrical tube separator. The electrolyte was a $1 \mathrm{M}$ $\mathrm{LiClO}_{4}$ (Aldrich, battery grade, 99.99\%, dried for 24 hours at $90{ }^{\circ} \mathrm{C}$ under vacuum) solution in propylene carbonate (PC) (Aldrich, 99.7\% Anhydrous). Batteries were submerged in a thermostated bath as shown in Fig. 1, and charged galvanostatically at $2 \mathrm{~mA} \mathrm{~cm} \mathrm{~cm}^{-2}$ for 8 or 24 hours in a glovebox sparged with argon $\left(\mathrm{H}_{2} \mathrm{O}, \mathrm{O}_{2}<0.5 \mathrm{ppm}\right)$. We estimated that (1) convection is negligible in our experiments since the value of the Rayleigh number $\mathrm{Ra}=$ 1708 at which convection sets in our system is estimated to be reached in layers of thickness $\delta>10 \mu \mathrm{m}$ (i.e., in the bulk electrolyte) that exceed the thickness of the electrochemical double layer where the relevant processes take place, ${ }^{61}$ (2) linear temperature gradients normal to the cathode are established within minutes (see ESI $\dagger$ ), (3) the limiting diffusional current density for discharging $1 \mathrm{M} \mathrm{Li}^{+}$in PC: $J \gg D C_{0} / L=78 \mathrm{~mA} \mathrm{~cm}{ }^{-2}$ is much larger than the $1 \mathrm{~mA} \mathrm{~cm}^{-2}$ value used in our experiments. ${ }^{62}$ 


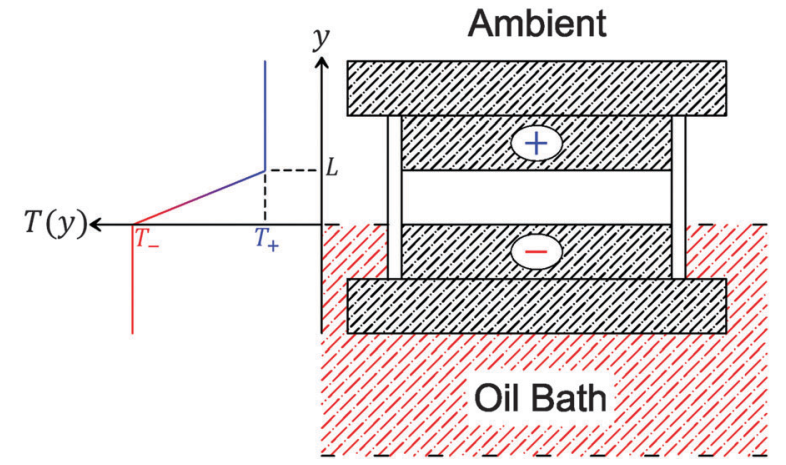

Fig. 1 Schematic diagram of the experiment setup. The initial steadystate temperature profile is shown on the left. See text.

After charging, batteries were removed from the glovebox for the acquisition of high-resolution digital images of the electrodeposits by means of a Leica 205FA microscope. The digital images of the three equiangular $120^{\circ}$ sectors of the curved peripheries of the cylindrical cells were then projected onto a flat surface as described in our previous publication. ${ }^{59}$ Forty five equidistant dendrites were selected from the projected images and sorted into $\left[n_{i}, \lambda_{i}\right]$ bins within specified length ranges $\lambda_{i}$. From this information we evaluated normalized average lengths, $\bar{\lambda}$, defined by eqn (1):

$$
\bar{\lambda}=\frac{\int n_{i} \lambda_{i}}{L \int n_{i}}
$$

that properly quantify the growth of dendrite populations generated by a stochastic process. The experimental $\left[n_{i}, \lambda_{i}\right]$ distributions are shown in Fig. 2. Fig. 3 shows plots of average lengths $\bar{\lambda}$ versus cathode temperature $T_{-}$.

Model calculations were based on our recently developed coarse-grained dynamical Monte Carlo (CG-MC) framework. ${ }^{46,63}$ The core 2D CG-MC algorithm calculates the combined diffusional and migrational $\mathrm{Li}^{+}$displacements using temperature dependent $\mathrm{Li}^{+}$diffusion coefficients, $D_{+}(T)$, and mobilities, $\mu_{+}(T)$, under local electric $\vec{E}(x, y, t)$ and temperature $T(x, y, t)$ fields ( $x$ and $y$ are the parallel and perpendicular coordinates to electrodes surfaces) (see below). $D_{+}(T)$ is assumed to follow an Arrhenius temperature dependence, eqn (2):

$$
D_{+}(T)=D_{+}^{0} \exp \left(-E_{\eta} / N k_{\mathrm{B}} T\right)
$$

From which we evaluate $\mu_{+}(T)$ by using the Stokes-Einstein relation, eqn (3):

$$
\mu_{+}(T)=\frac{e D_{+}(T)}{N k_{\mathrm{B}} T}
$$

$k_{\mathrm{B}}$ is Boltzmann's constant, $N$ is Avogadro's number, $e$ the elementary charge, and $E_{\eta}=13.5 \mathrm{~kJ} \mathrm{~mol}^{-1}$ the experimental activation energy derived from viscosity $\eta(T)$ data for the PC solvent (Table 1). Temperature $T(x, y, t)$ and electric field $\vec{E}(x, y, t)$ profiles were evaluated by finite-differences integration of the corresponding 2D Laplace's equations as described in our recent publication (see ESI, $\dagger$ for details). ${ }^{46}$ The surface of electrodeposits was set at $T_{-}$and $V_{-}$throughout, on account of the high $\mathrm{Li}^{\mathrm{O}}$
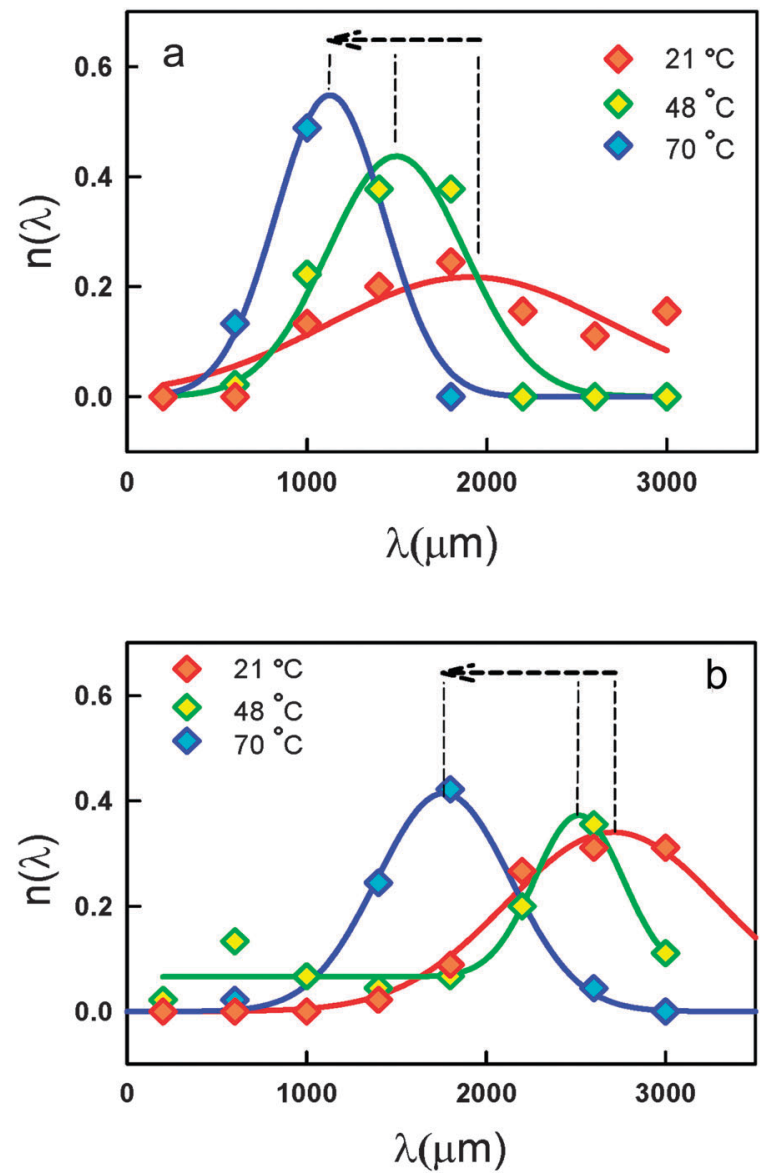

Fig. 2 Normalized dendrite length distributions $\left[n_{i}, \lambda_{i}\right]$ at various cathode temperatures $T_{-}$. Cells charged at $2 \mathrm{~mA} \mathrm{~cm}^{-2}$ for (a) $8 \mathrm{~h}$, (b) $24 \mathrm{~h}$.

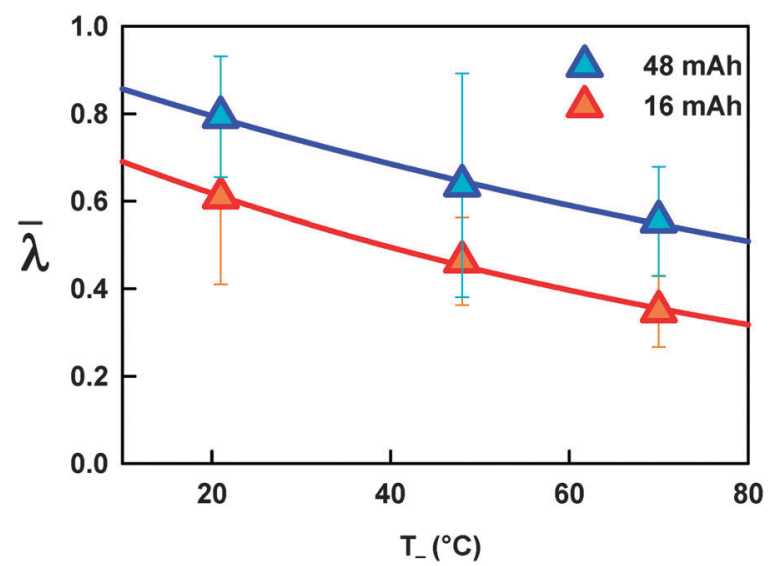

Fig. 3 Average dendrite lengths $\bar{\lambda}$ as fractions of interelectrode separation $L$ versus cathode temperature $T_{-}$.

electrical and thermal conductivities. CG-MC simulations were run in a $\left[L^{*} \times L^{*}\right], L^{*}=16.7 \mathrm{~nm}$, domain that approximately corresponds to the thickness of the depletion layers where the relevant events take place in this system (see Table 1). It is important to note that the actual $D_{+}(T)$ value used in the calculations was scaled down from experimental values $\left(D_{+}^{\exp }(300 \mathrm{~K})=2.58 \times 10^{-6} \mathrm{~cm}^{2} \mathrm{~s}^{-1}\right)^{62}$ for $\mathrm{Li}^{+}$diffusion in PC to 
Table 1 Parameters used in CG-MC calculations

\begin{tabular}{ll}
\hline Domain size & $L^{*} \times L^{*}=(17 \times 17) \mathrm{nm}^{2}$ \\
$V_{+}$ & $0 \mathrm{~V}$ \\
$V_{-}$ & $-47 \mathrm{mV}$ \\
$D_{+}^{0}$ & $3.4 \times 10^{-8} \mathrm{~cm}^{2} \mathrm{~s}^{-1}$ \\
$r_{+}$ & $1.19 \AA$ \\
$E_{\eta}$ & $13.5 \mathrm{~kJ} \mathrm{~mol}^{-1}$ \\
$\Delta E_{\mathrm{R}}^{\ddagger}$ & $20 \mathrm{~kJ} \mathrm{~mol}^{-1}$ \\
$p_{\mathrm{R}}^{0}$ & 300
\end{tabular}

yield diffusional displacements $\left\langle x^{2}\right\rangle^{1 / 2} \approx L^{* / 2}$ at the end of simulations. The rationale for such scaling has been described in a previous publication from our laboratory. ${ }^{46}$ Since the $\Delta t=$ $0.25 \mu$ s simulation time-step is much longer than the ps timescale of ion-ion collisions, $\mathrm{Li}^{+}$ions positions $\overrightarrow{\boldsymbol{r}}_{1}(t)$ were computed from average displacements given by eqn (4):

$$
\overrightarrow{\boldsymbol{r}_{l}}(t+\Delta t)=\overrightarrow{\boldsymbol{r}_{l}}(t)+\sqrt{2 D_{+}(T) \Delta t} \overrightarrow{\boldsymbol{g}}+\mu_{+}(T) \overrightarrow{\boldsymbol{E}}(\overrightarrow{\boldsymbol{r}}, t) \Delta t
$$

where $\overrightarrow{\boldsymbol{g}}$ is a random unit vector, and $\overrightarrow{\boldsymbol{E}}(\overrightarrow{\boldsymbol{r}}, t)$ is the position and time dependent electric field vector. The voltage drop across the $[16.7 \mathrm{~nm} \times 16.7 \mathrm{~nm}]$ domain: $V_{+}-V_{-}=47 \mathrm{mV}$, is scaled to generate the $\approx 10^{4} \mathrm{~V} \mathrm{~cm}^{-1}$ electric fields that make ion electromigration competitive with diffusion. ${ }^{34,46}$ We further assumed that $\mathrm{Li}^{+}$is reduced to $\mathrm{Li}^{0}$ with temperature-independent unit probability under the applied overpotentials. The actual parameters used in the simulations are listed in Table 1 (see below). Further details can be found in our previous publication. ${ }^{46}$

Since dendrites tips are intrinsically metastable formations possessing excess surface free energy relative to flat $\mathrm{Li}^{0}$ crystals, ${ }^{64,65}$ they should eventually relax via $\mathrm{Li}^{0}$-atom diffusion into interfacial sites of lower curvature/higher connectivity at sufficiently high temperatures. ${ }^{66,67}$ This relaxation process was incorporated into our model calculations by releasing $\mathrm{Li}^{0}$ atoms with probabilities $p_{\mathrm{R}}(T)$ given by eqn (5): ${ }^{66}$

$$
p_{\mathrm{R}}(T)=p_{\mathrm{R}}^{0} \exp \left(\frac{-\Delta E_{\mathrm{R}}^{\ddagger}}{N k_{\mathrm{B}} T}\right)
$$

$p_{\mathrm{R}}^{0}$ is an adjustable dimensionless pre-factor and $\Delta E_{\mathrm{R}}^{\dot{\phi}}$ is the effective activation energy for Li-atom hopping on our dendritic electrodeposits. The pre-factor was selected such that relaxation rates were competitive with deposition rates. We found that the temperature dependence of the $\bar{\lambda}(T)$ calculated in this manner was not overly sensitive to the value of the pre-factor, as long as the above condition was satisfied. At each integration step, $\mathrm{Li}^{0}$ atoms are released into the electrolyte as $\mathrm{Li}^{+}$ions at distances $4 r_{+}$ $\left(r_{+}=1.19 \AA\right.$ is $\mathrm{Li}^{+}$crystalline radius) away from the nearest surface $\mathrm{Li}^{0}$ atoms, which then evolve according to (eqn (3)). Each interfacial $\mathrm{Li}^{0}$-atom undergoes on average $4-5$ rearrangements per simulation. The dissolution of $\mathrm{Li}^{0}$ into $\mathrm{Li}^{+}$in close proximity of deposits followed by re-deposition is operationally equivalent to the diffusion of $\mathrm{Li}^{0}$ atoms from dendrite tips to concave regions. This is so because $\mathrm{Li}^{+}$ions released from dendrite tips have fewer neighboring surface sites to which return as $\mathrm{Li}^{0}$ than those released from concave cathode regions. Simulations were stopped the first time $400 \mathrm{Li}^{0}$ appeared the system. The total number of $\mathrm{Li}^{+}$ions was preserved by creating a new $\mathrm{Li}^{+}$at a random location whenever another $\mathrm{Li}^{+}$was annihilated as $\mathrm{Li}^{0}$. Calculated dendrite heights were quantified by dividing the $x$-axis in four sectors. Here, 'dendrite height' in each sector is the height of the uppermost $\mathrm{Li}^{0}$ defined by eqn (6):

$$
\lambda_{i}=\max _{k=1: n} \vec{\xi}_{k} \cdot \boldsymbol{j}
$$

where $\lambda_{i}$ is dendrite height, $\vec{\xi}_{k}$ the individual atoms coordinates in sector $i, n$ is the total number of lithium atoms incorporated into the dendrite in the corresponding sector and $\boldsymbol{j}$ is the unit vector in $y$ direction. To ensure good statistics, each simulation was run 10 times. From this information we evaluated $\bar{\lambda}$ values for comparison with experimental ones. Fig. 4 shows typical snapshots of calculated dendrites at three $T_{-}$values. In Fig. 5 computational $\bar{\lambda}$ values calculated by excluding and including surface relaxation are compared with experimental $\bar{\lambda}$ ones.

Our experimental results show that keeping the cathode warmer than the surrounding solution does inhibit dendrite growth. We have recently shown that the positive feedback underlying runaway dendrite growth is due to the fact that $\mathrm{Li}^{+}$ electromigration in the strong electric fields developing around high-curvature dendrite tips outpaces $\mathrm{Li}^{+}$diffusion to flatter regions. ${ }^{58}$ Since $D_{+}$and $\mu_{+}$increase exponentially with $T$, and the electrolyte filling concave pockets is significantly warmer than the layers surrounding dendrite tips (Fig. S1, ESI $\dagger$ ), we
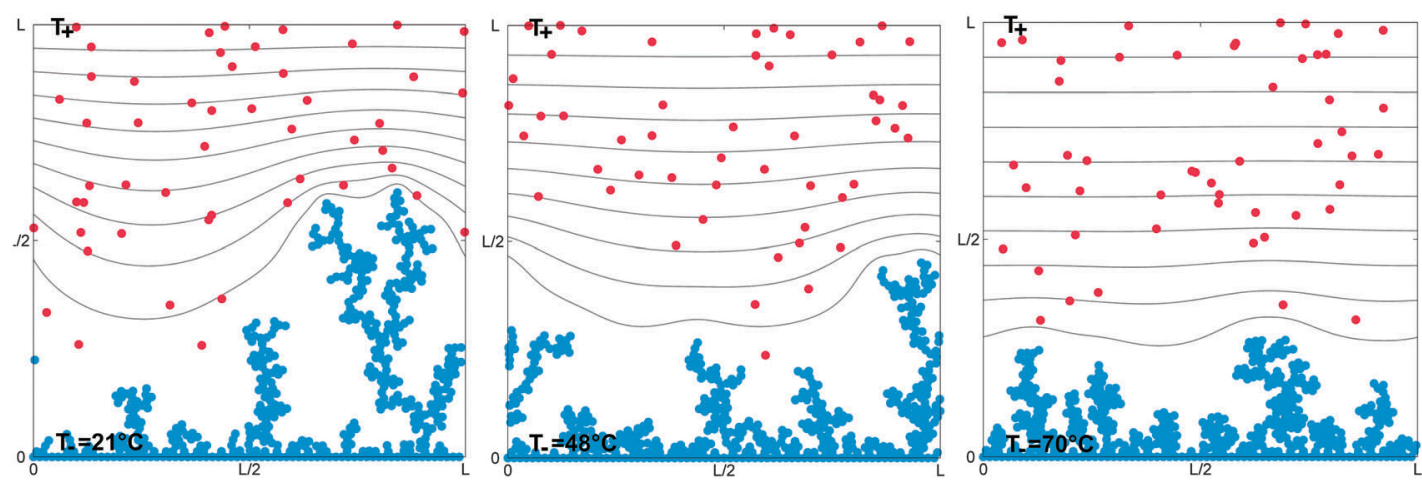

Fig. 4 Results of CG-MC calculations including both $\mathrm{Li}^{+}$transport and $\mathrm{Li}^{\mathrm{O}}$ thermal relaxation (see text). Blue dots: $\mathrm{Li}^{\circ}$ in dendrites. Red dots: $\mathrm{Li}^{+}$ions in solution. Gray lines are isotherms. From left to right, results at $T_{-}=21^{\circ}, 48^{\circ}$ and $70{ }^{\circ} \mathrm{C}$. 


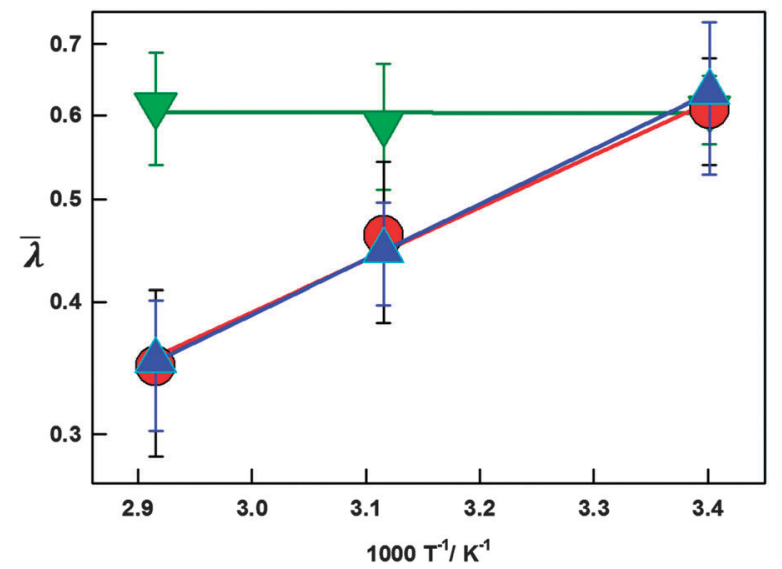

Fig. 5 Arrhenius $\log \bar{\lambda}$ vs. $1 / T$ plots. Red circles: experimental $\bar{\lambda}$ data obtained at $16 \mathrm{~mA}$ h (Fig. 2a); Green downward triangles: simulated $\bar{\lambda}$ by excluding dendrites relaxation. Blue upward triangles: simulated $\bar{\lambda}$ by including dendrites relaxation. Lines are linear regressions to the data. Simulated data (green and blue points) were pinned to the experimental value (red) at $21^{\circ} \mathrm{C}$ to help visualize slope differences.

expected that the application of negative temperature gradients to the cathode would enhance diffusionally-limited current densities to concave regions relative to dendrite tips. In other words, we expected that model simulations of the relatively faster $\mathrm{Li}^{+}$electrodeposition on cathode regions surrounded by warmer electrolyte layers would account for our experimental findings.

The results of GC-MC simulations (Fig. 5) dispelled our simplistic expectations. The reasons are that the $D_{+}(T), \mu_{+}(T)$ dependences originating from $E_{\eta}=13.5 \mathrm{~kJ} \mathrm{~mol}^{-1}$ (Table 1) are not only halved into diffusional $\bar{\lambda}(T)$ displacements, but they are also attenuated by the competition between ion diffusion and electromigration in the nonlinear $T(x, y, t), \vec{E}(x, y, t)$ and $\left[\mathrm{Li}^{+}(x, y, t)\right]$ fields surrounding the irregular $\mathrm{Li}^{0}$ deposits (Fig. 4). Thus, the results of Fig. 5 in effect implicate the participation of a process having a stronger temperature dependence that that associated with $\mathrm{Li}^{+}$transport in the electrolyte solvent. It was found that we could match the experimental $\bar{\lambda}(T)$ temperature trends by including the thermal relaxation of $\mathrm{Li}^{0}$ dendrites, as simulated by the process described above, with $\Delta E_{\mathrm{R}}^{\ddagger} \approx 20 \mathrm{~kJ} \mathrm{~mol}^{-1}$. The possibility that the formation of an insulating solid-electrolyte interfacial layer (SEI) could be responsible for our observations in apparently negated by the fully reversible galvanostatic curves we previously registered in this system upon successive charge-discharge cycles. ${ }^{59}$

A transition state theory (TST) analysis of atom diffusion in metallic solids provides a physical interpretation of our findings. ${ }^{68-70}$ The TST expression for the diffusion coefficient $D_{\mathrm{TST}}$ of Li-atoms on the surface of $\mathrm{Li}^{0}$ metal is given by eqn (7): ${ }^{54}$

$$
\begin{aligned}
D_{\mathrm{TST}} & =(1 / 4) a^{2} \frac{k_{\mathrm{B}} T}{h} \exp \frac{\Delta S^{*}}{N k_{\mathrm{B}}} \exp \left(-\frac{\Delta E^{*}}{N k_{\mathrm{B}} T}\right) \\
& =D_{\mathrm{TST}}^{0} \exp \left(-\frac{\Delta E^{*}}{N k_{\mathrm{B}} T}\right)
\end{aligned}
$$

where $a=3.49 \AA$ is the lattice constant, ${ }^{52} h$ is Planck's constant, and $\Delta S^{*}, \Delta E^{*}$ are the activation entropy and enthalpy of the process. Thus: $D_{\mathrm{TST}} \approx 2 \times 10^{-3} \mathrm{~cm}^{2} \mathrm{~s}^{-1} \exp \frac{\Delta S^{*}}{N k_{\mathrm{B}}} \exp \left(-\frac{\Delta E^{*}}{N k_{\mathrm{B}} T}\right)$ at $T_{1 / 2}=318 \mathrm{~K}$, the mean temperature in our experiments. By assuming that the shortening of dendrites at higher temperatures is due to Li-atom diffusion from dendrite tips to sites of higher coordination, we interpret that relative $\overline{\Delta \lambda(T)}=$ $\left\langle x^{2}\right\rangle_{T}^{1 / 2}-\left\langle x^{2}\right\rangle_{T=21^{\circ} \mathrm{C}}^{1 / 2}$ experimental decrements (from Fig. 2a) correspond in fact to average Li-atom diffusional displacements on the surface of dendrites. On this basis, from $D_{\exp }=$ $\overline{\Delta \lambda}^{2}(2 \tau)^{-1}, \tau=8 \mathrm{~h}$ we estimate an average experimental diffusion coefficient $D_{\exp } \approx 9 \times 10^{-8} \mathrm{~cm}^{2} \mathrm{~s}^{-1}$ at $T_{1 / 2}$. By identifying $D_{\mathrm{TST}}$ with $D_{\mathrm{exp}}$, and $\Delta E_{\mathrm{R}}^{\ddagger}$ with $\Delta E^{*}$ we derive a pre-factor $D_{\mathrm{TST}}^{0}=$ $4 \times 10^{-5} \mathrm{~cm}^{2} \mathrm{~s}^{-1}$ that is in the range of those typical for atom self-diffusion on metal surfaces, ${ }^{71-73}$ and leads to a significant negative entropy of activation: $\Delta S^{*}=-46 \mathrm{~J} \mathrm{~mol}^{-1} \mathrm{~K}^{-1}$, which is consistent with the transformation of (disordered) amorphous $\mathrm{Li}^{0}$ dendrites into $\mathrm{Li}^{0}$ crystals. ${ }^{74,75}$ Gratifyingly, the $\Delta E^{*}=$ $20 \mathrm{~kJ} \mathrm{~mol}^{-1}$ value derived from our experiments and CG-MC calculations falls within the range of the DFT values for the activation barriers of Li-atom hopping and exchange on $\mathrm{Li}(001)$ and Li(111) single crystals. ${ }^{52}$ The type of surface reconstruction we observe for metallic lithium dendrites above ambient temperatures is a universal phenomenon. ${ }^{66}$ For a melting point of bulk $\mathrm{Li}^{0}: T_{\mathrm{MB}}=180{ }^{\circ} \mathrm{C}=453 \mathrm{~K}$, the condition $T / T_{\mathrm{MB}}>0.7$ that determines the onset of surface reconstruction is already met by $\mathrm{Li}^{0}$ at $\approx 300 \mathrm{~K} .^{66}$ The above condition, which strictly applies to flat $\mathrm{Li}^{0}$ crystals, will be relaxed for microcrystalline dendrites because the melting point $T_{\mathrm{MD}}$ of dendrite tips of radius of curvature $\rho$ is necessarily lower than $T_{\mathrm{MB}}$. From the GibbsThompson equation that relates $T_{\mathrm{MD}}$ with $T_{\mathrm{MB}}$, eqn (8): ${ }^{76-78}$

$$
T_{\mathrm{MD}}=T_{\mathrm{MB}}\left(1-\frac{4 \sigma_{\mathrm{S}, \mathrm{L}}}{\Delta H_{\mathrm{MB}} d_{\mathrm{S}} \rho}\right)
$$

with solid-liquid surface energy $\sigma_{\mathrm{SL}}=0.41 \mathrm{~J} \mathrm{~m}^{-2},{ }^{79,80}$ melting enthalpy $\Delta H_{\mathrm{MB}}=512 \mathrm{Kg} \mathrm{m}^{-3}$, and solid density $d_{\mathrm{S}}=430 \mathrm{~kJ} \mathrm{Kg}^{-1}$, we estimate that, for example, the $T_{\mathrm{MD}}$ of conceivable dendrite tips sharper than $\rho<73 \mathrm{~nm}$ would be: $T_{\mathrm{MD}}<0.9 T_{\mathrm{MB}} \approx 400$ $\mathrm{K}=127^{\circ} \mathrm{C}$.

Summing up, our experiments and calculations open up the possibility that the runaway growth of electrolytic $\mathrm{Li}^{0}$ dendrites could be better controlled by increasing the mobility of Li-atoms on the solid than by increasing the mobility of $\mathrm{Li}^{+}$ ions in the electrolyte. They also suggest specific approaches, such as enhancing interfacial Li-atom diffusion by implanting extrinsic defects. ${ }^{70,81-84}$

\section{Acknowledgements}

Authors gratefully acknowledge support from the Bill and Melinda Gates Foundation Grant No. OPP1069500 on environmental sustainability and, in part, from Bosch Energy Research Network Grant No. 13.01.CC11. 


\section{References}

1 J. Rugolo and M. J. Aziz, Energy Environ. Sci., 2012, 5, 7151-7160.

2 M. Armand and J. M. Tarascon, Nature, 2008, 451, 652-657.

3 B. Dunn, H. Kamath and J.-M. Tarascon, Science, 2011, 334, 928-935.

4 W. Xu, J. L. Wang, F. Ding, X. L. Chen, E. Nasybutin, Y. H. Zhang and J. G. Zhang, Energy Environ. Sci., 2014, 7, 513-537.

5 H. Kim, G. Jeong, Y. U. Kim, J. H. Kim, C. M. Park and H. J. Sohn, Chem. Soc. Rev., 2013, 42, 9011-9034.

6 J. M. Tarascon and M. Armand, Nature, 2001, 414, 359-367. 7 J. B. Goodenough, Acc. Chem. Res., 2012, 46, 1053-1061.

8 J. B. Goodenough, J. Solid State Electrochem., 2012, 16, 2019-2029.

9 K. J. Harry, D. T. Hallinan, D. Y. Parkinson, A. A. MacDowell and N. P. Balsara, Nat. Mater., 2014, 13, 69-73.

10 R. L. Sacci, N. J. Dudney, K. L. More, L. R. Parent, I. Arslan, N. D. Browning and R. R. Unocic, Chem. Commun., 2014, 50, 2104-2107.

11 C. M. Lopez, J. T. Vaughey and D. W. Dees, J. Electrochem. Soc., 2009, 156, A726-A729.

12 H. Liu, F. C. Strobridge, O. J. Borkiewicz, K. M. Wiaderek, K. W. Chapman, P. J. Chupas and C. P. Grey, Science, 2014, 344, 1480.

13 T. R. Ferguson and M. Z. Bazant, Electrochim. Acta, 2014, 146, 89-97.

14 J. Owen and A. Hector, Science, 2014, 344, 1451-1452.

15 M. S. Whittingham, Chem. Rev., 2014, 114, 11414-11443.

16 K. Xu, Chem. Rev., 2004, 104, 4303-4418.

17 J. Steiger, D. Kramer and R. Monig, J. Power Sources, 2014, 261, 112-119.

18 Y. Y. Lu, Z. Y. Tu and L. A. Archer, Nat. Mater., 2014, 13, 961-969.

19 M. Z. Mayers, J. W. Kaminski and T. F. Miller III, J. Phys. Chem. C, 2012, 116, 26214-26221.

20 J. L. Barton and J. O. M. Bockris, Proc. R. Soc. London, Ser. A, 1962, 268, 485-505.

21 C. Monroe and J. Newman, J. Electrochem. Soc., 2003, 150, A1377-A1384.

22 P. C. Howlett, D. R. MacFarlane and A. F. Hollenkamp, J. Power Sources, 2003, 114, 277-284.

23 N. Schweikert, A. Hofmann, M. Schulz, M. Scheuermann, S. T. Boles, T. Hanemann, H. Hahn and S. Indris, J. Power Sources, 2013, 228, 237-243.

24 O. Crowther and A. C. West, J. Electrochem. Soc., 2008, 155, A806-A811.

25 C. Brissot, M. Rosso, J. N. Chazalviel, P. Baudry and S. Lascaud, Electrochim. Acta, 1998, 43, 1569-1574.

26 I. W. Seong, C. H. Hong, B. K. Kim and W. Y. Yoon, J. Power Sources, 2008, 178, 769-773.

27 G. Stone, S. Mullin, A. Teran, D. Hallinan, A. Minor, A. Hexemer and N. Balsara, J. Electrochem. Soc., 2012, 159, A222-A227.

28 D. R. Ely and R. E. Garcia, J. Electrochem. Soc., 2013, 160, A662-A668.
29 F. Ding, W. Xu, G. L. Graff, J. Zhang, M. Sushko, X. Chen, Y. Shao, M. H. Engelhard, Z. Nie and J. Xiao, J. Am. Chem. Soc., 2013, 135, 4450-4456.

30 C. M. Lopez, J. T. Vaughey and D. W. Dees, J. Electrochem. Soc., 2012, 159, A873-A886.

31 C. Monroe and J. Newman, J. Electrochem. Soc., 2004, 151, A880-A886.

32 J. T. Vaughey, G. Liu and J. G. Zhang, MRS Bull., 2014, 39, 429-435.

33 J. Steiger, D. Kramer and R. Moenig, Electrochim. Acta, 2014, 136, 529-536.

34 J. N. Chazalviel, Phys. Rev. A: At., Mol., Opt. Phys., 1990, 42, 7355-7367.

35 S. Schnur and A. Groß, Catal. Today, 2011, 165, 129-137.

36 J. Steiger, G. Richter, M. Wenk, D. Kramer and R. Mönig, Electrochem. Commun., 2015, 50, 11-14.

37 G. Richter, K. Hillerich, D. S. Gianola, R. Monig, O. Kraft and C. A. Volkert, Nano Lett., 2009, 9, 3048-3052.

38 M. Schamel, C. Schopf, D. Linsler, S. T. Haag, L. Hofacker, C. Kappel, H. P. Strunk and G. Richter, Int. J. Mater. Res., 2011, 102, 828-836.

39 R. F. Sekerka, Cryst. Res. Technol., 2005, 40, 291-306.

40 Z. Li, J. Huang, B. Yann Liaw, V. Metzler and J. Zhang, J. Power Sources, 2014, 254, 168-182.

41 P. Novák, R. Imhof and O. Haas, Electrochim. Acta, 1999, 45, 351-367.

42 H. D. Yoo, I. Shterenberg, Y. Gofer, G. Gershinsky, N. Pour and D. Aurbach, Energy Environ. Sci., 2013, 6, 2265-2279.

43 M. Mohtadi and F. Mizuno, Beilstein J. Nanotechnol., 2014, 5, 1291-1311.

44 T. J. Richardson and G. Chen, J. Power Sources, 2007, 174, 810-812.

45 C. Ling, D. Banerjee and M. Matsui, Electrochim. Acta, 2012, 76, 270-274.

46 A. Aryanfar, D. Brooks, B. V. Merinov, W. A. Goddard, A. J. Colussi and M. R. Hoffmann, J. Phys. Chem. Lett., 2014, 5, 1721-1726.

47 J. W. Diggle, A. R. Despic and J. O. Bockris, J. Electrochem. Soc., 1969, 116, 1503-1514.

48 M. Z. Bazant, Acc. Chem. Res., 2013, 46, 1144-1160.

49 Y. S. Cohen, Y. Cohen and D. Aurbach, J. Phys. Chem. B, 2000, 104, 12282-12291.

50 V. Fleury, Nature, 1997, 390, 145-148.

51 T. A. Witten and L. M. Sander, Phys. Rev. Lett., 1981, 47, 1400-1403.

52 M. Jäckle and A. Groß, J. Chem. Phys., 2014, 141, 174710.

53 T. M. Trimble and R. C. Cammarata, Surf. Sci., 2008, 602, 2339-2347.

54 A. Groß, Theoretical Surface Science - A Microscopic Perspective, Springer, Berlin, 2nd edn, 2009.

55 H. Brune, Surf. Sci. Rep., 1998, 31, 125-229.

56 H. Jónsson, Annu. Rev. Phys. Chem., 2000, 51, 623-653.

57 K. Doll, N. M. Harrison and V. R. Saunders, J. Phys.: Condens. Matter, 1999, 11, 5007-5019.

58 A. Aryanfar, US Pat., 14/201,979, 2014. 
59 A. Aryanfar, D. J. Brooks, A. J. Colussi and M. R. Hoffmann, Phys. Chem. Chem. Phys., 2014, 16, 24965-24970.

60 K. Nishikawa, T. Mori, T. Nishida, Y. Fukunaka, M. Rosso and T. Homma, J. Electrochem. Soc., 2010, 157, A1212-A1217.

61 F. P. Incropera and D. P. Dewitt, Introduction to Heat Transfer, Wiley, New York, NY, 6th edn, 2011.

62 P. K. Muhuri and D. K. Hazra, J. Chem. Eng. Data, 1994, 39, 375-377.

63 K. A. Fichthorn and W. H. Weinberg, J. Chem. Phys., 1991, 95, 1090-1096.

64 R. Akolkar, J. Power Sources, 2013, 232, 23-28.

65 S. Chandrashekar, N. M. Trease, H. J. Chang, L.-S. Du, C. P. Grey and A. Jerschow, Nat. Mater., 2012, 11, 311-315.

66 H. Brune, Ann. Phys., 2009, 18, 675-698.

67 C. M. Lopez, J. T. Vaughey and D. W. Dees, J. Electrochem. Soc., 2009, 156, A726-A729.

68 C. Kittel, Elementary Statistical Physics, John Wiley \& Sons, New York, 8th edn, 2004.

69 W. D. J. Callister and D. G. Rethwisch, Fundamentals of materials science and engineering: an integrated approach, Wiley, Hoboken, NJ, 4th edn, 2012.

70 A. Grazyna, Surface diffusion: metals, metal atoms, and clusters, Cambridge University Press, New York, NY, 2010.
71 E. G. Seebauer and C. E. Allen, Prog. Surf. Sci., 1995, 49, 265-330.

72 T. Alanissila and S. C. Ying, Prog. Surf. Sci., 1992, 39, 227-323.

73 D. A. Reed and G. Ehrlich, Surf. Sci., 1981, 102, 588-609.

74 S. Y. Chang, C. E. Li, Y. C. Huang, H. F. Hsu, J. W. Yeh and S. J. Lin, Sci. Rep., 2014, 4, 4162.

75 L. P. H. Jeurgens, Z. M. Wang and E. J. Mittemeijer, Int. J. Mater. Res., 2009, 100, 1281-1307.

76 J. Sun and S. L. Simon, Thermochim. Acta, 2007, 463, 32-40.

77 P. R. Couchman and W. A. Jesser, Nature, 1977, 269, 481-483.

78 L. W. Wang, Philos. Mag., 2013, 93, 3648-3663.

79 B. B. Alchagirov, L. K. Afaunova, F. F. Dyshekova, A. G. Mozgovoi, T. M. Taova and R. K. Arkhestov, High Temp., 2009, 47, 287-291.

80 A. A. V. Grosse, J. Inorg. Nucl. Chem., 1964, 26, 1349-1361.

81 P. Ehrhart, P. Jung and H. Schultz, Atomic Defects in Metals, Springer, Berlin Heidelberg, 1991.

82 A. T. Ribes, P. Beaunier, P. Willmann and D. Lemordant, J. Power Sources, 1996, 58, 189-195.

83 Q. S. Mei and K. Lu, Philos. Mag. Lett., 2008, 88, 203-211.

84 R. A. Huggins, J. Power Sources, 1999, 81, 13-19. 